\title{
A Historical Systems Study of Liquid Rocket Engine Throttling Capabilities
}

\author{
Erin M. Betts ${ }^{*}$ \\ National Aeronautics and Space Administration, Huntsville, AL, 35812 \\ and \\ Dr. Robert A. Frederick, Jr. ${ }^{\dagger}$ \\ University of Alabama in Huntsville, Huntsville, AL, 35899
}

This is a comprehensive systems study to examine and evaluate throttling capabilities of liquid rocket engines. The focus of this study is on engine components, and how the interactions of these components are considered for throttling applications. First, an assessment of space mission requirements is performed to determine what applications require engine throttling. A background on liquid rocket engine throttling is provided, along with the basic equations that are used to predict performance. Three engines are discussed that have successfully demonstrated throttling. Next, the engine system is broken down into components to discuss special considerations that need to be made for engine throttling. This study focuses on liquid rocket engines that have demonstrated operational capability on American space launch vehicles, starting with the Apollo vehicle engines and ending with current technology demonstrations. Both deep throttling and shallow throttling engines are discussed. Boost and sustainer engines have demonstrated throttling from $17 \%$ to $100 \%$ thrust, while upper stage and lunar lander engines have demonstrated throttling in excess of $10 \%$ to $100 \%$ thrust. The key difficulty in throttling liquid rocket engines is maintaining an adequate pressure drop across the injector, which is necessary to provide propellant atomization and mixing. For the combustion chamber, cooling can be an issue at low thrust levels. For turbomachinery, the primary considerations are to avoid cavitation, stall, surge, and to consider bearing leakage flows, rotordynamics, and structural dynamics. For valves, it is necessary to design valves and actuators that can achieve accurate flow control at all thrust levels. It is also important to assess the amount of nozzle flow separation that can be tolerated at low thrust levels for ground testing.

\section{Nomenclature}

$\begin{aligned} A_{e} & =\text { nozzle exit area } \\ A_{t} & =\text { throat area } \\ c^{*} & =\text { characteristic efficiency } \\ C_{d} & =\text { injector orifice discharge coefficient } \\ c_{f} & =\text { thrust coefficient } \\ F & =\text { thrust } \\ g & =\text { Earth's gravitational constant } \\ I_{s p} & =\text { specific impulse } \\ K & =\text { compressible flow constant } \\ L^{*} & =\text { characteristic length } \\ \dot{m} & =\text { mass flow rate } \\ N & =\text { pump rotor speed }\end{aligned}$

$\begin{array}{ll}p & =\text { pressure } \\ p_{a} & =\text { atmospheric pressure } \\ p_{c} & =\text { chamber pressure } \\ p_{e} & =\text { nozzle exit pressure } \\ p_{w} & =\text { wall pressure } \\ Q & =\text { volumetric flowrate } \\ \rho & =\text { density } \\ V_{c} & =\text { chamber volume } \\ v_{e} & =\text { nozzle exit gas velocity }\end{array}$

\footnotetext{
* Systems Engineer, ER21 Liquid Engine Systems Branch NASA Marshall Space Flight Center, Huntsville, AL 35812.

${ }^{\dagger}$ Professor, Mechanical and Aerospace Engineering, 5000 Technology Drive, TH S226, Huntsville, AL 35899, AIAA Associate Fellow.
} 


\section{Introduction}

$\mathrm{L}$ IQUID rocket engine throttling has been and will be critical to achieve the necessary mission requirements that the National Aeronautics and Space Administration (NASA) demands. Throttling has been required on past missions, and has been demonstrated on many engines such as the Apollo Lunar Module Descent Engine (LMDE), the RL-10 and its derivatives, and the Space Shuttle Main Engine (SSME). Throttling can be used to accomplish many different space flight functions including boost phase trajectory tailoring, load reduction, orbital rendezvous, and planetary descent. When required, it is important to consider the impacts to the engine system that result from incorporating throttleability. Some of these impacts include a decrease in performance and efficiency, and an increase in weight, size, complexity, and cost. The benefits of a highly throttleable engine must be weighed against program and system constraints.

Liquid rocket engine throttling is defined as varying the thrust of the rocket engine in reference to the $100 \%$ Rated Power Level (RPL). Throttling down to about a ratio of 4:1 thrust (25\% RPL) is considered to be "shallow throttling," and can be readily accomplished with little or no modification to a fixed thrust engine. Typically, a highpressure drop injector can be used in order to achieve shallow throttling, with minimal consequences to the engine and feed systems. Throttling beyond 4:1 thrust is considered "deep throttling," and more cost and design creativity must be used.

The key difficulty in throttling liquid rocket engines is maintaining an adequate pressure drop across the injector, which is necessary to provide propellant atomization and mixing. ${ }^{1}$ In addition to maintaining good combustion in the combustion chamber, is it critical to evaluate the key rocket engine components such as the thrust chamber, turbomachinery, valves, and nozzle to ensure each component is adequately designed for the range of thrust that is required of the engine. For the combustion chamber, cooling can be an issue at low thrust levels. For turbomachinery, the primary considerations are to avoid cavitation, stall, surge, and to consider bearing leakage flows, rotordynamics, and structural dynamics. For valves, it is necessary to design valves and actuators that can achieve accurate flow control at all thrust levels. For the nozzle, it is important to assess the amount of flow separation that can be tolerated at low thrust levels for ground testing.

The NASA Exploration Systems Architecture Study (ESAS) was performed over a period of 90 days in 2005 in order to assess crew and cargo launch systems to explore the moon and Mars. ${ }^{2}$ The vision outlined in the ESAS study potentially would require throttling on a lunar descent engine and upper stage engine. A throttling range of 10:1 is likely to be required in order to achieve the lunar landing mission. Shallow throttling would be required of the boost or upper stage engine. The use of an SSME, J-2 derivative, or RL-10 derivative engine would allow for ease of throttle development.

Although NASA has been proceeding down the path outlined by the Constellation Program per the Bush Administration's direction, President Obama's proposed NASA budget for Fiscal Year (FY) 2011 exhibits a different vision. ${ }^{3}$ With the proposed FY 2011 budget, liquid rocket engine throttling could be required as a part of the flagship demonstration programs, which could include "critical technologies such as in-orbit propellant transfer and storage, inflatable modules, automated/autonomous rendezvous and docking, closed-loop life support systems, and other next-generation capabilities." ${ }^{3}$ Heavy lift and propulsion R\&D activities could also include extensive research on throttling capabilities of liquid rocket engines. If new advanced propulsion systems are used, many of these systems have elements that are common to liquid rocket engines, such as turbopumps and nozzle cooling systems. Throttling with these advanced systems would have similar issues associated with liquid rocket engine throttling, thus making the study of liquid rocket engine throttling relevant.

Considering both the 2005 ESAS Constellation architecture and NASA's FY 2011 proposed budget, a strong case can be made that it is important for the future of NASA to ensure liquid rocket engine throttling technology is developed beyond the state of the art.

This study evaluates different engines that have been throttled in the past, followed by a breakdown of components in order to discuss special considerations that need to be made for engine throttling. The focus of this study is on the major liquid rocket engine components, and how the interactions of these components as a system need to be considered for throttling applications. 


\section{Background}

\section{A. Throttling Equations}

In order to begin the discussion on throttling liquid rocket engines, it is first necessary to understand the basic thrust equation. The thrust equation contains both a momentum exchange term and pressure balance term to describe overall engine thrust,

$$
F=\dot{m} v_{e}+\left(p_{e}-p_{a}\right) A_{e} .
$$

In this equation, $F$ is thrust, $\dot{m}$ is mass flow rate through the nozzle, $v_{e}$ is the velocity of the hot gas at the exit of the nozzle, $p_{e}$ is the pressure at the exit of the nozzle, $p_{a}$ is the pressure of the atmosphere immediately outside the nozzle, and $A_{e}$ is the nozzle exit area.

When evaluating this equation, it can be observed that the thrust can be decreased if ambient pressure is increased, or if mass flow rate, exit velocity, exit pressure, or exit area is decreased. Varying the nozzle exit area is difficult to achieve, since high thermal loads would possibly inhibit the mechanical features of a moveable nozzle. ${ }^{4}$ Varying the propellant flow rates has been shown to be a favorable way to vary thrust; several methods for varying propellant flow rates in an effort to throttle the engine are discussed throughout this evaluation.

When throttling an engine, the key is to reduce the thrust and chamber pressure of the rocket by reducing the upstream propellant mass flow rates and still maintaining adequate pressure drop over the injector so that combustion stability can be achieved. Looking at the mass flow equations for incompressible and compressible flow, the following is true,

$$
\begin{gathered}
\text { Incompressible Flow (liquid) }: \dot{m}=C_{d} A \sqrt{2 \rho \Delta p} \text {, and } \\
\text { Compressible Flow (gas): } \dot{m}=K \Delta p,
\end{gathered}
$$

where $A$ is the total injector orifice cross-sectional area, $C_{d}$ is the injector orifice discharge coefficient, $\rho$ is the propellant density, and $\Delta p$ is the pressure drop over the injector. $K$ is a compressible flow constant. The mass flow rate and $\Delta p$ are directly proportional for gaseous propellants, while the mass flow rate is proportional to the square root of $\Delta p$ for liquid propellants.

Another relationship is

$$
\dot{m}=\frac{p_{c} A_{t}}{c^{*}}
$$

where $A_{t}$ is the throat area and $c^{*}$ is the characteristic velocity. The $c^{*}$ velocity is only dependent on the thermochemical reactions in the combustion chamber and is a function of the ratio of specific heats, the gas constant, and the stagnation temperature. Often times, the $c^{*}$ efficiency is discussed; this efficiency is defined as

$$
c * \text { efficiency }=\frac{c{ }^{*} \text { Actual }}{c * \text { Pr edicted }}
$$

In simple terms, $c^{*}$ efficiency represents the amount of energy that is extracted out the combustion process, and it typically varies from about $96 \%$ to $98 \%$ at RPL. It is common for the $c^{*}$ efficiency to decrease as the engine is throttled, however for this assessment, the decrease in efficiency can be assumed to be small enough that it will not significantly affect the relationships discussed herein. That being said, assuming a constant $c^{*}$ and $A_{t}$, it can be observed that the mass flow rate and chamber pressure are directly proportional.

From historical and experimental results, the "general rule of thumb" is that the nominal ratio of injector pressure drop to chamber pressure should be around $15-20 \%$ in order to achieve and maintain stable combustion. ${ }^{6}$

$$
\text { Pressure Ratio For Stable Combustion: } \frac{\Delta p}{p_{c}} \geq 15 \%
$$

The relationship in Equation (6) is a good preliminary design goal. However, it is not a firm requirement, as there have been engines that have operated at a $\Delta p / p_{c}$ less than $15 \%$ while still achieving stable combustion characteristics, while in other cases, engines can exhibit a low frequency combustion instability commonly referred to as chug operating at a $\Delta p / p_{c}$ higher than $15 \%$. 


\section{Liquid Propellant Flow}

For liquid phase propellants, as the mass flow rate decreases, it is assumed that $C_{d}, A$, and $\rho$ in Equation (2) are held constant for a constant flow area injector. As the mass flow rate decreases, the chamber pressure decreases proportionally. As the mass flow rate and chamber pressure decrease, so does the square root of the pressure drop over the injector.

$$
\text { Incompressible Flow (liquid): } \dot{m} \propto p_{c} \propto \sqrt{\Delta p}
$$

As the engine is throttled, the mass flow rate of propellant through the injector is decreased, as does the pressure drop over the injector. The chamber pressure decreases at a rate of the power of 2 greater than the rate at which the pressure drop decreases. Thus, as the engine is throttled, the ratio of $\Delta p / p_{c}$ decreases.

Gaseous Propellant Flow

Looking at gaseous propellant flow, referencing Equation (3) for compressible flow for a gas, it can be seen that with a constant $K$, the pressure drops proportionally with the mass flow rate.

$$
\text { Compressible Flow (gas): } \dot{m} \propto p_{r} \propto \Delta p
$$

Thus, the pressure ratio stays constant even at low power levels. This simplifies the injector design for gaseous propellant throttling since a reasonable $\Delta p / p_{c}$ is achievable at all power levels without putting stringent requirements on the propellant feed system.

Specific Impulse

In terms of specific impulse, $I_{s p}$, it is understood that

$$
I_{S P}=\frac{F}{\dot{m} g}
$$

At lower thrust levels, the $I_{s p}$ decreases. While the mass flow rate decreases as thrust decreases, the thrust decreases at a greater rate, resulting in a loss of $I_{s p}$ as the engine is throttled. Another way to express $I_{s p}$ is

$$
I_{s p}=\frac{c^{*} c_{f}}{g} \text {. }
$$

In Equation (10), $c_{f}$ is the thrust coefficient, and is a function of the ratio of specific heats, chamber pressure, ambient pressure, and expansion ratio. It reflects the product-gas expansion properties and design quality of the nozzle. As thrust decreases, the expansion quality decreases, and the thrust coefficient decreases. As a result, the $I_{s p}$ decreases at lower thrust levels.

Mixture ratio also plays a role in the specific impulse of the engine. For each engine, there exists an optimum mixture ratio where deviations from the optimum result in lower $I_{s p}$. This optimum mixture ratio is affected by stay time of the burning gas in the combustion chamber, cooling considerations, and propellant density. ${ }^{7}$

An example of this effect is shown in Figure 1, which is a plot of the Common Extensible Cryogenic Engine (CECE) test data. There exists a mixture ratio for optimal $I_{s p}$ at each thrust level. At all mixture ratios, as the thrust level is decreased, the $I_{s p}$ decreases. 


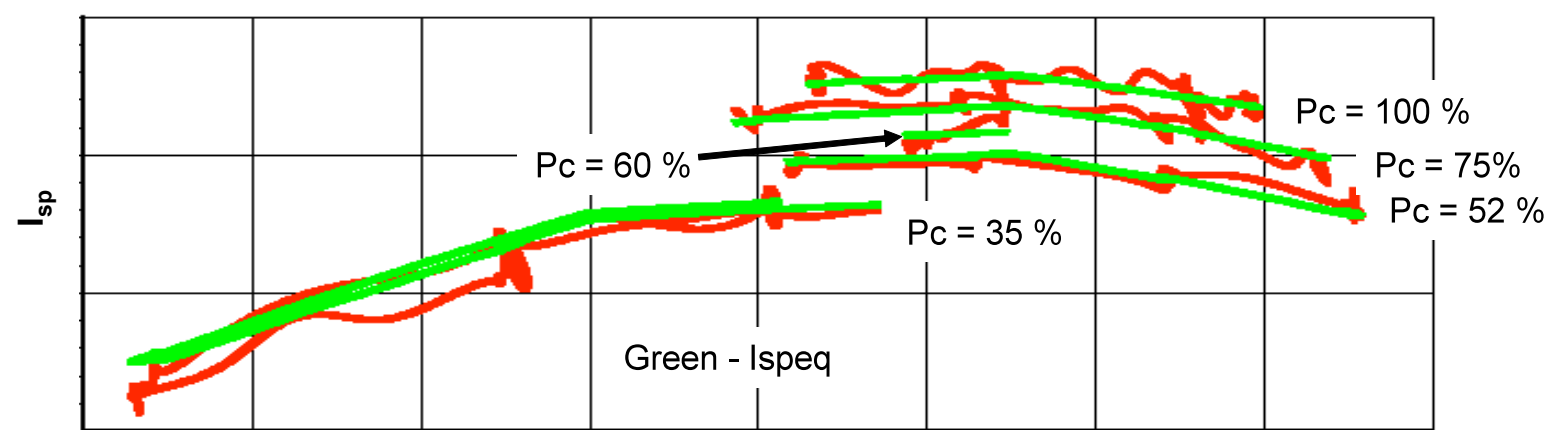

Mixture Ratio

Figure 1: CECE $I_{\text {sp }}$ vs. Thrust ${ }^{8}$

Considering the J-2X, the engine is designed to operate at 448 seconds $I_{s p}$ at $100 \%$ thrust for the primary power level, and at 450 seconds $I_{s p}$ at $81 \%$ thrust for the secondary burn. This initially seems to contradict the discussion above, however the primary reason for an increase in $I_{s p}$ at the lower thrust is the optimized mixture ratio for the secondary burn. Due to feed system and vehicle constraints, it isn't always feasible to operate at the optimal mixture ratio for $I_{s p}$ during all phases of flight. A balance can be achieved between the feed system, mixture ratio and the desired thrust level in order to achieve a desired $I_{s p}$.

\section{B. Approaches to Throttling}

Once the physics and the equations for throttling are understood, it is useful to understand demonstrated approaches to liquid rocket engine throttling. Gordon Dressler ${ }^{9}$ and Matthew Casiano ${ }^{6}$ have both written AIAA papers that address throttling approaches. Combining the ideas in these two papers, liquid propellant rocket engine throttling methods are presented below. It is important to note that for shallow throttling, one method alone may be employed for throttling. However, as deeper throttling requirements are imposed on a system, several throttling solutions are typically used together. In particular, some additional throttling mechanisms, such as inert gas injection, can be turned on for use when needed at low power levels if the engine can otherwise achieve its objectives without the additional system at higher thrust levels. It is common for the cost of an engine to increase substantially as deeper throttling requirements are imposed due to added mechanical and system design complexity and testing that are required to achieve the mission goals. The six identified methods for liquid rocket engine throttling are:

\section{Using a high-pressure-drop injection system with propellant flow regulation}

One way to achieve an adequate pressure ratio at both low and high power levels is to design the injector to have a high-pressure drop at the full power level. Using a high-pressure drop injector for full thrust allows for enough pressure drop to be maintained at low power levels. One issue with this method is that at full thrust, sometimes unreasonably high pressure requirements are imposed on the feed system or the engine is forced to operate at a lower chamber pressure than desired. Due to the limitations that exist with using a high-pressure drop injector, applications are commonly limited to shallow throttling engines such as the SSME. As the throttle range increases, it is desirable to start with a high-pressure drop injector, but additional system modifications are likely to be required.

One advantage of using a high-pressure drop injector is its operational simplicity. Although multi-element injectors can be difficult to manufacture and require tight tolerances on very small geometries, one injector is required for each engine, and it requires little to no maintenance once it is installed. The absence of mechanically actuated devices and control systems for the injector allows for simple operation, however, if a high-pressure drop injector is coupled with additional dynamic throttling aids, the complexity of the system can increase.

2. Varying the injection element area by the use of selectable manifolds or movable injector elements.

This method uses injector area variation to achieve engine throttling. By varying the flow area of the injected fluids, it is feasible to achieve the desired flow velocities in the combustion chamber while maintaining adequate pressure drop at all thrust levels. This allows for optimized injection at all power levels without having to impose stringent requirements on the feed system or reducing chamber pressure. ${ }^{6}$ 
A dual or multiple stage injector consists of two or more injector stages that are in series with one another. At low power levels, valves can be used to stop flow to one of the injector stages, thus limiting the propellant flow to a single injector stage. This allows for better optimization of the injection system at both high and low power levels in order to keep the feed system requirements and combustion stability in check. The Lunar Lander Descent Engine Testbed (LLDET) at the Marshall Space Flight Center (MSFC) is currently testing two different dual stage injector designs to evaluate the performance characteristics in an effort to develop the technology necessary for a new Lunar Lander Descent Engine. ${ }^{10}$

When considering dual or multiple stage injectors, it is clear that a step change occurs when one injector is turned off. It is important to understand the system affects when the injector is turned off, since this action could induce combustion instability and large heat fluxes in a marginally stable system. Complicated purging must be incorporated for the non-operating stage orifices in order to prevent backflow of propellant and combustion gases. ${ }^{9}$

Pintle injection is another form of variable injection area throttling. The pintle injector is mechanically actuated to achieve the proper flow area and stable injection characteristics at all power levels. A Pintle injector was used on the Apollo LMDE engine, ${ }^{11}$ and although it requires mechanical actuation, the pintle can be a simple component to manufacture. One key characteristic of the pintle is its inherent combustion stability at all power levels. ${ }^{12}$ An example of a variable-area pintle injector from the LMDE is shown in Figure 2.

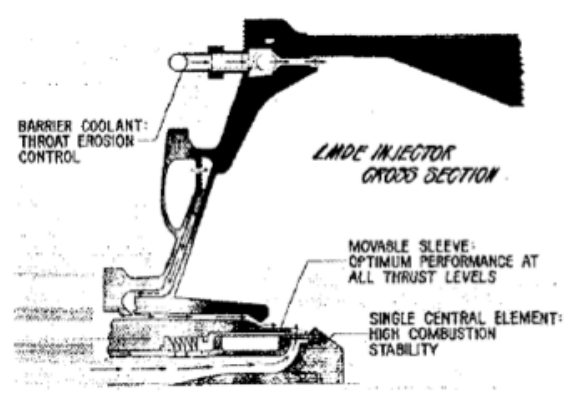

Figure 2: Cross-Section of the LMDE Pintle Injector ${ }^{12}$

\section{Inert Gas injection to decrease fluid density injected into the system}

Inert gas injection injects an inert gas such as Helium directly upstream of the LOX manifold in the LOX dome. As the gas is injected into the system, the density of the LOX is decreased significantly, which raises the pressure drop over the injector. With gas injection, the pressure drop is increased without affecting the mass flow rate. The volume void fraction of the gas and liquid mixture could increase significantly by increasing the gas mass flow rate by a relatively small amount, while the gas quality (or mass of the gas relative to the total mass) would remain very small. ${ }^{13}$ This is a proven way to keep the pressure ratio high even at low thrust, thus eliminating chug. However, caution must be used when employing this method, since "Russian experience reports that gas injection can lead to the onset of high frequency pressure fluctuations.",

Disadvantages to this method are that it requires additional complexity in the feed system, and system compliance can be impacted, which can lead to instabilities other than chug. Also, Helium is quite expensive, so using large amounts of Helium is not always economical.

\section{Use of multiple combustion chambers}

Using a single feed system, two or more combustion chambers can be used to achieve the desired thrust. Chambers can be turned on or off in order to control overall thrust, or each chamber can be optimized to a smaller throttle ratio in order to achieve a net throttling affect. The RD-180 uses multiple chambers to meet the durability and high performance requirements of the Atlas vehicle. ${ }^{14}$ For engines such as the RD-180 that are driven by a single set of turbomachinery, many of the system effects that are present in the single chamber configuration are still present using multiple chambers. Some issues that can arise from this throttling method include a changing thrust reaction point on the vehicle and added system complexity and weight. The use of multiple chambers, however, allows for a decrease in engine length, which is desirable for some missions.

\section{Varying nozzle throat area}

Varying the throat area is a technique that can be used to vary thrust; this method is called "throat throttling." This can be achieved by mechanically restricting the throat area or by using a gas to vary the throat area. "Both methods effectively changed the throat area by providing some blockage into the flow field. Both modes have a net effect on decreasing thrust, since at constant propellant pressures, a throat restriction causes an increase in chamber pressure and hence lower injection pressure drops and reduced propellant flow rates.",

This is more likely an option for smaller thrusters rather than large boost engines due to the mechanical difficulties and high heat fluxes and structural loading that the throat experiences during engine operation. Also, large changes in throat area are required in order to affect small changes in thrust. ${ }^{9}$ 


\section{Design to Avoid Throttling}

Due to difficulties with liquid rocket engine throttling, it is typical that design teams will attempt to think of ways to avoid throttling. Alternate methods that have been used in the past include pulse modulation, using multiple engines, and vehicle design. Sometimes, however, the vehicle can become too complex if throttling is avoided.

\section{Throttleable Engines}

Despite the difficulties associated with throttling, it has been successfully achieved on numerous liquid rocket engines. This study focuses on three engines in particular, which span a range of cycles, thrusts, and throttling ranges. These three engines are the Lunar Module Descent Engine, RL-10 and derivatives, and Space Shuttle Main Engine.

\section{A. Lunar Module Descent Engine (LMDE)}

The development of the Lunar Module Descent Engine began in 1963 at TRW Systems in support of the Apollo missions to the moon. The LMDE was instrumental in the lunar landings of Apollo 11, 12, 14, 15, 16, and 17. It also returned the astronauts to Earth after the service module failure on Apollo 13. ${ }^{15}$

Some of the key requirements for the LMDE include accurate thrust and mixture ratio control, accurate propellant injection control to maintain optimum performance and combustion stability, ability to perform multiple, space-vacuum restarts at $10 \%$ or higher throttle level without startup ignition spikes and without hydraulic instabilities, and high reliability. ${ }^{12}$

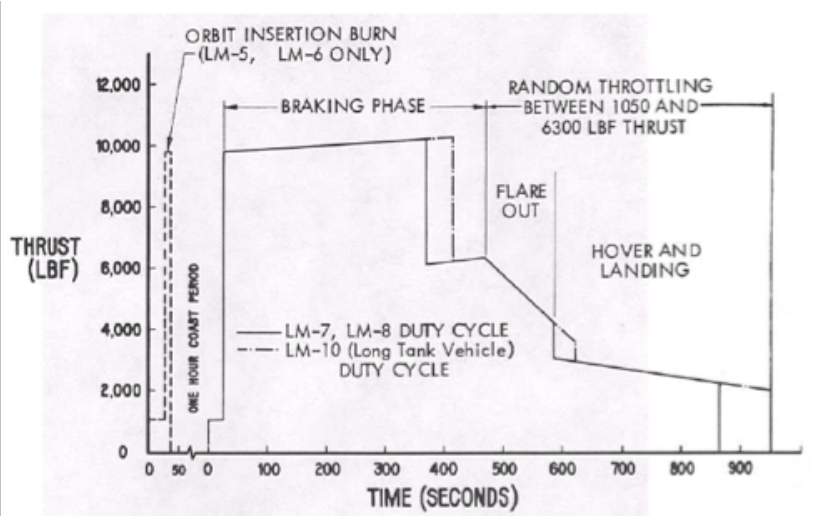

Figure 3: LMDE Nominal Duty Cycle ${ }^{9}$

The LMDE is a pressure-fed engine that uses the earth-storable hypergolic bipropellants nitrogen tetroxide $\left(\mathrm{N}_{2} \mathrm{O}_{4}\right)$ and Aerozine 50/50 $\left(\mathrm{N}_{2} \mathrm{H}_{4} / \mathrm{UDMH}\right)$. The LMDE achieves a maximum thrust of 10,000 lbf with a vacuum $I_{s p}$ of about 305 seconds at maximum thrust. The simplicity of the LMDE and the use of hypergolic propellants increases the reliability of the engine, although the hypergolic propellants cannot achieve the high $I_{s p}$ that is achieved using liquid hydrogen and liquid oxygen propellants.

The LMDE is required to perform the thrust profile shown in Figure 3, with a throttle ratio of 10:1. This was the first engine to successfully demonstrate 10:1 throttling on a manned space flight mission.

The unique design features of the LMDE allow for this wide performance range. These features include a variable area pintle injector and cavitating venturi flow

control valves. The use of these features together isolates the propellant flow control function from the propellant injection function, which allows for optimization of each function without compromising the other. The pintle injector that is used on this engine is discussed in further detail in the Injector section of this paper. The LMDE never experienced sustained high-frequency instability, which is primarily attributed to the inherent stability of the pintle injector design. $^{12}$

\section{B. RL-10 and Derivatives}

The RL-10 development began in 1958 by Pratt \& Whitney. ${ }^{16}$ The RL-10 has proven to be a very versatile engine, and has survived over five decades to be a proven, highly throttleable and highly reliable engine. The RL-10 has evolved for several different applications, including use as an upper stage on the Titan III, Titan IV, Delta III, Atlas I, Atlas II, Atlas IIA, and Atlas IIAS. It was also used for the

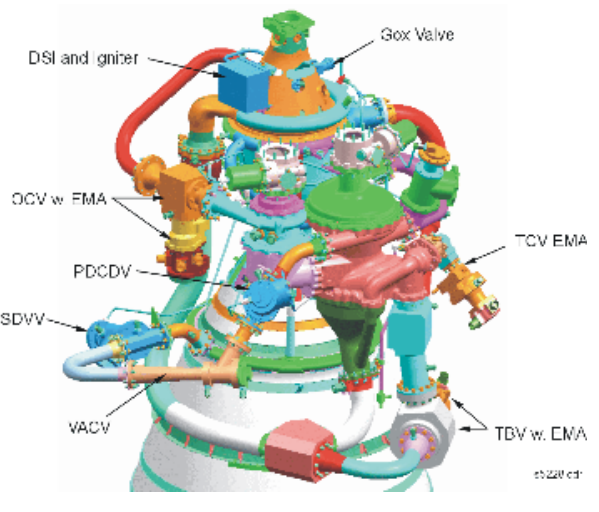

Figure 4: RL-10 CECE Unique Valve Configuration ${ }^{8}$ 
being tested at Pratt \& Whitney Rocketdyne in West Palm Beach, Florida. The CECE is the "RL-10" focus of this study since it is a recent, relevant engine that has successfully demonstrated throttling in excess of $10: 1^{8}$. The maximum thrust of the CECE is about 15,000 lbf.

The RL-10 has demonstrated the ability to operate using a number of different propellant combinations, including Fluorine/Hydrogen, Flox/Methane, and LOX/Propane, in addition to the baseline LOX/Hydrogen. The key requirements that the RL-10 was designed to were low cost, high reliability, and simple control.

The RL-10 uses a closed expander cycle. ${ }^{17}$ The fuel pump pumps the cold fuel through the combustion chamber coolant tubes. The gas is heated through the heat transfer process as it flows through the regenerative coolant tubes, and is routed through the turbine to power the turbopump assembly. A single turbine is used with a geared LOX and Hydrogen pump assembly. The expander cycle is quite benign, which is advantageous in particular to the turbine; the low turbine temperatures allow the RL-10 to use lightweight materials to keep engine weight to a minimum. This is in sharp contrast to high temperature turbines that are driven directly by combustion gases, such as those used in the SSME.

Key features of the CECE allow the engine to achieve throttling. These are turbine bypass valve (TBV), thrust control valve (TCV), RL-10 venturi, cavitating venturi, and variable oxidizer control valve (OCV). Figure 4 shows the CECE unique valve configuration.

\section{Space Shuttle Main Engine (SSME)}

The SSME development effort was started in 1971 by NASA and was funded and managed at MSFC. The Rocketdyne division of Rockwell was brought on as the prime contractor to begin work in April of 1972. After nine years of development and testing, three SSMEs flew on the inaugural Space Transportation System (STS) mission, and every STS mission since then. The key SSME requirements include "reusability, high performance, accurate thrust and mixture ratio control, and very high reliability." 18 The SSME Flow Schematic is shown in Figure 5.

The SSME is a staged combustion, reusable LOX/Hydrogen liquid propellant rocket engine. The rated power level is 470,000 pounds vacuum thrust with a chamber pressure of 3,006 psia. The engine is capable of operation between $65 \%$ and $109 \%$ RPL, which translates to 305,500 to 512,300 pounds vacuum thrust and 1,954 to 3,276 psia chamber pressure. The area ratio is 77.5 , the vacuum specific impulse is calculated to be 453.5 seconds, and the engine operates with a nominal mixture ratio (ratio of oxygen to hydrogen) of $6.0 .^{19}$ Staged combustion "provides for the total use of the propellants by burning the turbopump turbine exhaust products in the main combustion chamber and expanding all of the hot gas through the chamber and nozzle, thereby extracting the maximum energy." 18

The SSME throttling requirements originate from the throttle-back maneuver when the Space Shuttle Vehicle reaches 3g's

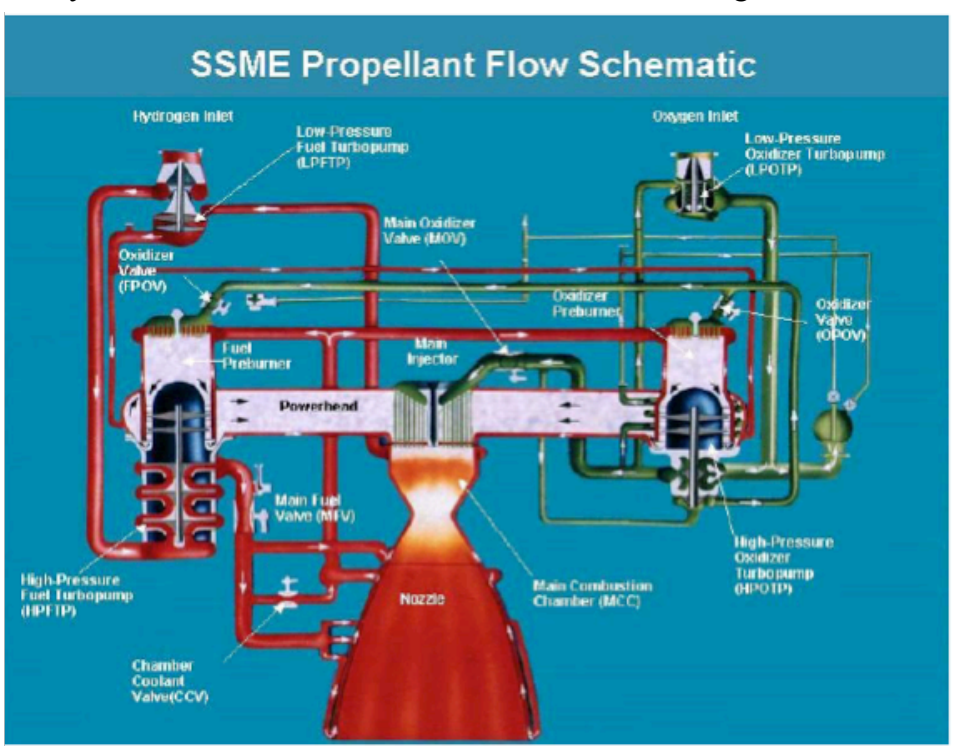

Figure 5: SSME Propellant Flow Schematic ${ }^{19}$ acceleration. This is done in order to prevent excessive heating and loading on the vehicle during ascent. Although throttling during flight is only required to $67 \%$, tests have been performed on the SSME to demonstrate its capability to throttle down as low as $17 \% .{ }^{20}$ SSME "throttling and power level operation is achieved by varying the fuel preburner oxidizer valve (FPOV) for mixture ratio control and the oxidizer preburner oxidizer valve (OPOV) for power level control.,20

Historically, some of the issues experienced by the SSME during throttled conditions include nozzle flow separation, side loads and heat loads; preburner boost pump bistability (around 50\% RPL); HPOTP preburner vane diffuser stall (prior to Block II upgrade); and HPFTP boilout (stall) at very low (dwell) mixture ratios. The SSME did not exhibit unstable combustion characteristics even at power levels as low as $17 \%{ }^{20}$ 


\section{Engine Summary}

Table 1 summarizes the liquid rocket engines that are studied herein.

Table 1: Summary of Throttling Liquid Rocket Engines

\begin{tabular}{|c|c|c|c|}
\hline & LMDE & RL10/CECE & SSME \\
\hline \multicolumn{4}{|l|}{ Performance } \\
\hline Max Vacuum Thrust (lbf) & 10,000 & 15,000 & 470,000 \\
\hline Vacuum ISP (sec) & 305 & 445 & 453.5 \\
\hline Throttle Ratio & 10 -to-1 $(10 \%$ to $100 \%)$ & 10 -to-1 $(10 \%$ to $100 \%)$ & 5.88-to-1 (17\% to $109 \%)$ \\
\hline \multicolumn{4}{|l|}{ Design Features } \\
\hline Cycle & Pressure Fed & Closed Expander Cycle & Fuel-Rich Staged Combustion \\
\hline Propellants & $\mathrm{N}_{2} \mathrm{O}_{4}$ and Aerozine $50 / 50$ & $\mathrm{LO}_{2}$ and $\mathrm{LH}_{2}$ & $\mathrm{LO}_{2}$ and $\mathrm{LH}_{2}$ \\
\hline Turbopumps & None & Geared, driven by fuel turbine & $\begin{array}{l}2 \text { separate low pressure and high } \\
\text { pressure pumps, independently } \\
\text { driven. }\end{array}$ \\
\hline Injector & Pintle & Multi-element injector & $\begin{array}{l}\text { High pressure drop, multi- } \\
\text { element shear co-axial injector }\end{array}$ \\
\hline
\end{tabular}

\section{Engine Components}

Throttling is an engine systems issue that impacts each component in the liquid rocket engine. The previous section described brief details of three throttleable engines. These three engines are now evaluated with a discussion of the separate engine components, and particular issues that may be encountered with a given component. It is important to evaluate the engine cycle that is used and the component interactions, along with the propellants that are used in order to achieve an understanding of how the system will operate at varied thrust levels. Although predictions are useful in the design phase, it is of the utmost importance to invest in a thorough test program that allows for component and engine system testing to understand the limitations of the hardware.

\section{A. Injector}

The liquid rocket engine injector is one of the most sensitive and complex components of the engine. The purpose of the injector is to inject "the propellants into the combustion chamber in the right proportions and the right conditions to yield an efficient, stable combustion process." ${ }^{7}$ Injector design consists of a fine balance between combustion stability, injector element size and number, combustion efficiency, manufacturing complexity, and cost.

Proper propellant atomization, vaporization, and mixing is the primary design goal of the injector; setting a high enough pressure drop over the injector ensures high propellant velocities to achieve good propellant atomization and mixing once the propellants enter the combustion chamber. Propellant velocities and injection patterns are also optimized for proper combustion.

As discussed previously, a typical "rule of thumb" when designing an injector is to keep the ratio of LOX injector pressure drop to chamber pressure around $15-25 \%$. While a low pressure drop minimizes the injector weight and requirements on the feed system, the pressure drop needs to be high enough in order to prevent communication between the chamber gases and the feed system, which leads to instabilities.

When throttling liquid rocket engines, two primary combustion instabilities issues may arise; chug and LOX boiling.

\section{Chug}

One problem that is typical of development throttling engines is a phenomenon called chug. Chug is a low frequency instability that occurs between 10 and $400 \mathrm{~Hz}$. It is commonly driven by communication between propellant combustion in the combustion chamber and fluid dynamics just upstream of the injector in the propellant feed system. Employing adequate pressure drop over the injector can usually eliminate chug. Additional methods of avoiding chug are using dual element injectors, gas-gas injection, and high inertia injectors. ${ }^{21}$ Chugging is particularly a problem at low thrust on the RL-10 CECE.

Chug is also dependent on mixture ratio. Gas injection can be turned on at the low thrust levels that are susceptible to chug in order to eliminate the chug. As discussed above, the purpose of gas injection is to increase the pressure drop over the injector by lowering the density of the injected fluid. Referring back to Equation (2), for a given mass flow rate of propellant, assuming constant $C_{d}$ and $A$, when the gas is injected into the LOX dome, the 
injected LOX becomes a mixture of LOX and gas, with a density that is considerably lower than LOX alone. Since density and pressure drop are inversely related, as the density decreases, the pressure drop increases. Thus, with gas injection, adequate pressure drops can be achieved at low power levels such that chug can be avoided. This was successfully demonstrated using Helium injection on the RL10. ${ }^{22}$

One disadvantage of gas injection is that the gas has a tendency to "soften" the system by increasing the system's capacitance. This can counteract some of stability benefits of the pressure drop gained by using gas injection. Instabilities can also be caused if the gas is not injected into the system correctly or if the gas is not a clean, homogeneous mixture. If the flow rate of the gas is not sufficient, it may not be effective. While the gas flow rate matters, gas temperature does not have an affect on chug. LOX boiling can also contribute to chug, primarily due to the fact that the LOX boiling increases the system compliance.

\section{LOX Boiling}

LOX boiling is a concern that needs to be considered for deep throttling engines. The LOX enters the LOX cavity of the injector, which is often located adjacent to the fuel injector cavity. In expander cycle engines, the LOX can experience boiling. At lower thrust levels, the pressures in the LOX dome are lower than they are at full thrust. If the pressure drops below the LOX critical pressure, LOX boiling can occur. Also, heat transfer from the fuel feed side can increase the likelihood for LOX boiling. Boiling in the LOX dome is highly undesirable since it can lead to combustion instabilities. The feed temperature of the LOX impacts its likelihood for boiling.

One fix that can be incorporated into the design is to insulate the LOX from the fuel in order to prevent heat transfer from the warm fuel to the LOX. Another method for mitigating this concern is to inject an inert gas just upstream of the LOX injection point in an effort to decrease the overall LOX density and in effect raise the pressures in the LOX dome. Inert gas injection is not only beneficial to achieve an adequate pressure drop over the injector, but it also can be useful in preventing LOX boiling and associated instabilities from occurring.

\section{Injector Types}

Several different types of injectors can be used in throttleable engines. In this study, the high $\Delta p$ single stage multi-element injector, pintle injector, and two or multistage injectors are considered.

\section{High Delta Pressure Single Stage Multi-element Injector}

The high $\Delta p$ single stage multi-element injector is a common injector in American engine designs. The SSME and RL-10 engines use high-pressure drop single stage multi-element injectors in order to achieve throttling. Using a high $\Delta p$ injector allows for adequate pressure drop at low power levels so that combustion stability can be achieved. Multi-element injectors consist of a series of LOX posts that are brazed into the injector faceplate. One propellant is injected down the center orifice of each LOX post. This is typically the more dense propellant. The propellant flow is either axial or swirling after being injected through a series of slots or holes on the LOX posts. The second propellant is injected in an axial sheet around the outer circumference of the LOX post. The use of numerous LOX posts allows for adequate atomization, mixing, and vaporization of the propellants upon entering the combustion chamber.

Multi-element injectors typically exhibit good performance and efficiency. However, they are typically limited to use with shallow throttling applications such as boost or sustainer engines. With lower thrust upper stage or landing engines that require deep throttling, additional throttling aids are often required.

Different types of elements include shear co-axial elements (such as those on the SSME) and swirl co-axial elements (such as those on the RL-10). It has been demonstrated that better mixing of the propellants can be achieved when using swirl co-axial elements rather than shear co-axial injector elements. Adding swirl can be as simple as machining the LOX post LOX entrance holes at an angle in order to achieve LOX swirl. With minimal added complexity, better mixing and propellant impingement can be achieved at all power levels.

\section{Single Element Pintle Injector}

The pintle injector is used in the LMDE engine. The pintle is a mechanically actuated piston that changes the propellant injection area for different thrust levels. This allows for precise control of the amount of propellants injected into the chamber, and is one of the reasons the LMDE was so successful. The pintle injector can also be used in a fixed thrust engine, with the added simplicity of eliminating the pintle actuation system. Since as few as five piece parts can be used for the injector assembly, the manufacturing and assembly of the injector can be quite simple compared to multi-element injectors. 
With the pintle injector, one propellant is injected through a series of injection orifices in the center pintle piece. The other propellant is injected as an axial sheet concentrically around the pintle. It is essentially one large injection element, as shown in Figure 6. If the fuel is adequately sprayed toward the combustion chamber walls, it can both mix with the oxidizer and cool the inside wall of the chamber. One highly desirable feature of the pintle injector is its inherent combustion stability. Even at power levels as low as $10 \%$, the pintle injector has never exhibited acoustic instability. ${ }^{9}$

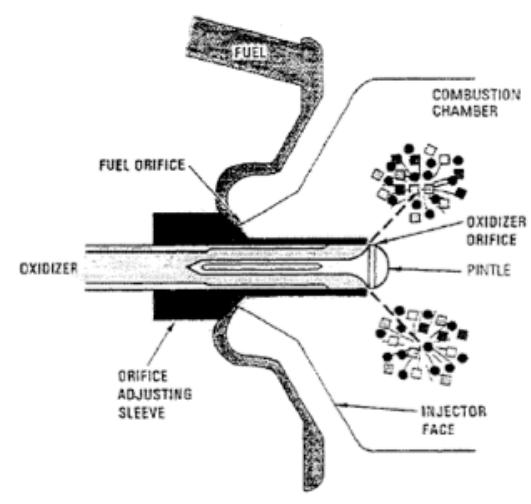

Figure 6: Pintle Injector ${ }^{11}$

One downside to using pintle injectors is the relatively low combustion efficiency. It is common for recirculation areas to form at the base of the pintle. This can turn into a dead-flow region, and can cause some loss of efficiency. The chamber length must be designed to be long enough to allow for the propellants to mix adequately. The temperatures at the pintle tip need to be evaluated, and the tip material must be selected so that the material does not melt with the high combustion chamber temperatures.

With these issues taken into consideration, pintle injectors typically do not exhibit the high efficiency that can be achieved with multi-element injectors. However, in some cases, it is worth taking the loss in efficiency in order to reap the benefits of the inherent combustion stability of this configuration for throttling applications.

Two or Multi-stage Multi-element Injectors

The idea of using two or multiple stage multi-element injectors takes advantage of the benefits of the high efficiency of the multi-element injector design and the area variation achieved using the pintle injector. Using several stages allows for certain stages or certain elements to be turned off at low power levels in an effort to keep the pressure drop over the injector high without having to put stringent requirements on the feed system. As mentioned previously, this is a relatively new area of research that is currently being investigated on MSFC's LLDET.

Some issues with multi-stage injectors include injector system complexity. Manufacturing a multi-element injector can be difficult, so manufacturing a system with multiple stages and valves to turn injection orifices on and off becomes more cumbersome. Also, the injectors that are turned off need to be purged so that hot combustion gases and propellants do not backflow into the injector orifices. However, if consistently good performance and feed system flexibility can be achieved, this could be an excellent option for use on a throttling engine.

\section{E. Thrust Chamber}

The thrust chamber consists of the volume between the injector faceplate and the throat where the combustion process takes place. In order to ensure that combustion stability is achieved, the thrust chamber must be designed such that the length is long enough to ensure proper mixing and combustion of the propellants. If the length is too short and the propellants exit the chamber without mixing and combusting, performance is lost. Propellants are expensive to store and pump through the engine, so any amount of propellant that is lost and is not burned to produce thrust is a costly performance loss.

Combustion chamber volume is designed considering propellant mass flowrate, average specific volume, and the propellant stay time. Chamber length is often characterized as $L^{*}$, which is referred to as the "characteristic length." $L *$ is defined as

$$
L^{*}=\frac{V_{c}}{A_{t}}
$$

where $V_{c}$ is the chamber volume and $A_{t}$ is the throat area. As $L^{*}$ is increased, the $c^{*}$ also increases, to a limit. When choosing an appropriate $L^{*}$, one must consider the length available in the engine design envelope, the weight available for the combustion chamber, and how much $c^{*}$ efficiency is actually needed to execute the mission. It also must be understood that increasing the $L^{*}$ creates more surface area that needs to be cooled; thermal losses could increase. Larger $L^{*}$ could also increase "the frictional losses in the combustion chamber, reducing nozzle stagnation pressure and resultant thrust.",

Chamber length also impacts the design of cold flow side, the fuel in the coolant tubes, particularly in expander cycle engines such as the RL-10. At low thrust levels, the mass flow rate of fuel pumped to cool the chamber 
decreases. As a result, the resonant time of the fuel in the regenerative tubes increases, and the fuel heats up more than at higher thrust levels due to increased heat transfer to the fuel through the tubes. In some cases, fuel jacket boiling can occur. Fuel jacket boiling begins when the temperature rises above the critical temperature or when the pressure drops below the critical pressure of the fuel. This can either be driven by heat transfer or by a decrease in pressure due to lower flow rates. Thus, it is important for the fuel to stay above the critical pressure and below the critical temperature of the fuel. The reason fuel jacket boiling is undesirable is because it can lead to combustion instabilities. It can also impact the turbine performance since the turbine is just downstream of the coolant tubes. One way to avoid fuel jacket boiling is by using a flow control or venturi valve downstream of the coolant tubes. This can provide enough back pressure at the low power levels to maintain pressures above the fuel critical pressure so that fuel jacket boiling can be avoided.

\section{E. Turbomachinery}

Turbomachinery systems for liquid rocket engines are very complex devices in terms of mechanical components and flow characteristic. They operate at very high speeds and produce an enormous amount of power.

The SSME turbopumps are particularly impressive. The SSME has 4 different turbopumps; a Low Pressure Oxidizer Turbopump (LPOTP), a High Pressure Oxidizer Turbopump (HPOTP), a Low Pressure Fuel Turbopump (LPFTP), and a High Pressure Fuel Turbopump (HPFTP). The HPFTP main shaft rotates at 37,000 rpm, and the HPFTP generates $100 \mathrm{hp}$ for each pound of its weight. The HPFTP provides the fuel to the regeneratively cooled nozzle, and the HPFTP and HPOTP provide the LOX and hydrogen to the HPOTP and HPFTP preburners, which in turn drive the high-pressure pumps.

The RL-10 turbopumps are driven by a common fuel turbine. The LOX and fuel pumps are geared to achieve the proper mixture ratio of propellants. The mixture ratio, however, does not have to remain constant. On the CECE, the mixture ratio is varied by the use of an OCV that regulates the flow of oxidizer while maintaining fuel flow on the fuel pump. The TBVs used on CECE control the $\mathrm{p}_{\mathrm{c}}$ and thus the power level while allowing the turbopump to remain above the stall region.

Turbomachinery for throttling engines is designed for full thrust. When operating off the rated power level, special considerations need to be made for cavitation, rotordynamics, structural dynamics, bearings and fuel leakage flows, stall and velocity triangles, and surge.

\section{Cavitation}

Cavitation occurs when the local pressure at the blade is less than the vapor pressure of the fluid. "The term cavitation refers to conditions within the pump where, owing to a local pressure drop, cavities filled with...vapor are formed; these cavities collapse as soon as the vapor bubbles reach regions of higher pressure on their way through the pump. ${ }^{23}$ The reason cavitation is undesirable is it can lead to structural damage and flow surges. Cavitation damage can be very difficult to eliminate and expensive to fix. It can decrease the performance of the pump, and impact the steady state and the unsteady or dynamic response of the fluid flow. ${ }^{24}$ It can eventually lead to pump head fall-off, which is highly undesirable.

One study from the 1960s used propellant that was tapped off from the pump discharge and re-routed back through the pump in an effort to "improve flow distribution and suppress cavitation and instabilities that occur when the turbopump is throttled." ${ }^{25}$ This is an interesting concept that proved to be somewhat successful, with some challenges that would need to be overcome in order to be truly successful. "Both the [flow] oscillation amplitude and frequency are significantly reduced when inlet fluid injection is used, since cavitation is suppressed until lower suction pressures are reached." ${ }^{25}$ It is also noted that "during noncavitating conditions unstable flow also was avoided when fluid injection prevented inducer stall and flow reversals at low flow coefficients. 25

One method that is commonly used to characterize cavitation is called the "bucket curve," which shows the suction performance as a function of $Q / N$, where $Q$ is the volumetric flow rate and $N$ is the pump speed. As the engine is throttled to lower power levels, the pump characteristic $Q / N$ decreases. The curve defines the boundary between cavitating and non-cavitating flow. As the pump operates below the bucket curve, less pump head is generated, and the pump moves into deeper cavitation zones. As the performance dips below the bucket curve, the vapor propagates down the blade, and the blade becomes less effective and eventually ineffective. It is critical to understand this cavitation boundary as the flow coefficient is decreased at low power levels.

Another way to evaluate the system is by looking at the "knee curve," which shows the pump head rise as a function of cavitation number. As the cavitation number decreases, it eventually reaches a point where pump head can no longer be achieved. This is referred to as "head falloff." It is important to maintain a cavitation number that is greater than the head falloff cavitation number, with some margin. 


\section{Rotordynamics}

Turbomachinery rotordynamics must be carefully evaluated for a throttling engine turbopump. It is critical to stay either above or below critical resonant modes of the turbopump. In order to assess the system, both linear and nonlinear rotordynamic analyses must be performed. During thrust ramp-up and ramp-down, moving through certain modes cannot be avoided; often times if the system moves through a mode relatively quickly, no effects are realized by the system. "Rotordynamic stability is another design issue requiring not only damping devices but also minimizing the destabilizing forces. Excessive vibration prevention due to unbalance, etc., is another design task. Gates for rotordynamic stability margins and vibration levels are required. The turbine can have the same kind of issues including disk mode instability, flutter of turbine blades, etc., which must be prevented and require gates as well. Bearing wear is also a design issue. The gate on bearings can be a trade between lifetime and maintenance (bearing replacement)." 26

Rotordynamics consider the forces acting upon the turbomachinery components due to the rotating assembly, and interactions between the fluids and structural components. The system responds through the bearings, and the system must be designed such that the bearings can withstand the loads at both high and low rotational speeds. Typically, the rotordynamic radial loads increase with speed, leading to wear and life concerns. The deflections also tend to increase with speed, leading to concerns about rub. "Operation of turbomachinery at or near a natural frequency causes excessive response, increases wear, and reduces reliability. Synchronous motion coincident with the rotor natural frequency is defined as operation at a critical speed. The dynamic response can be reduced by increasing the effective damping or designing the rotor to locate its natural frequencies far from the shaft-spin-speed excitation." 7

At different speeds, different modes can be excited. The different modes impart different deflections on the shaft. These modes can be controlled through the design of the shaft assembly and the housing to ensure minimal deflections and to ensure adequate bearing life for the demands of a particular engine. This is typically accomplished by design the rotating assembly to operate below the critical speed. When throttling is needed, the operational speed range increases, and thus a greater range of modes need to be evaluated. Turbomachinery is balanced to the $100 \%$ thrust configuration, so when operating off this $100 \%$ thrust design point, sometimes additional instabilities from the rotor assembly can be experienced. ${ }^{27}$

The risk of encountering rotordynamic instabilities can be mitigated through proper material selection, the use of blade dampers to ensure proper damping of the structural modes, and appropriate shaft stiffness. Shrouds can also be added as stability aids.

\section{Structural Dynamics}

Structural strength requirements are critical for turbopump life considerations. The turbomachinery "must meet durability requirements that include lowand high-cycle fatigue, fracture, flutter/vortex shedding, acoustics, and creep. ${ }^{, 26}$ If not designed correctly, the turbopump assembly can experience cracks, individual component failure, and fatigue failure.

Primary strength margins and low cycle fatigue limitations must be assessed. First, the operating speed ranges for flight are calculated. Then, the modes of all the components are calculated. Then, it is determined if the generated forces exceed the strength or excessively excite the modes of each part. These excitation intersections are usually shown in a Campbell Diagram where the modal excitation frequency vs. selected multiples of rotor speeds are identified. An example of a Campbell Diagram ${ }^{28}$ is shown in Figure 7.

As an engine is throttled, a larger speed and

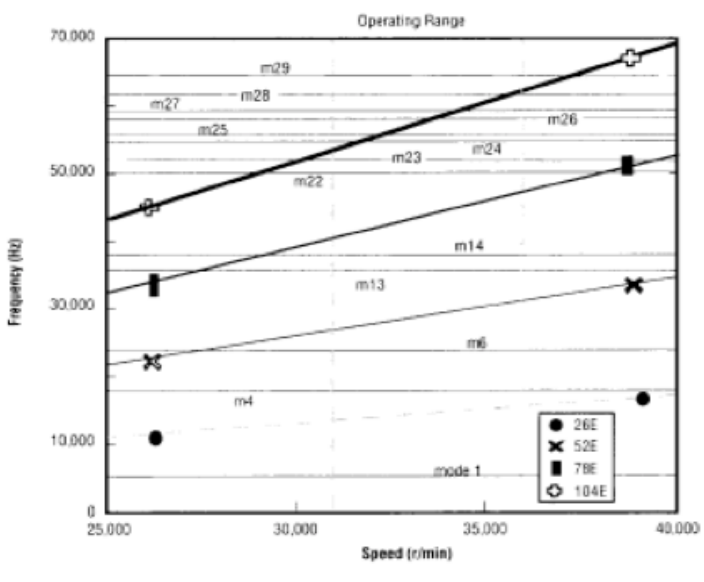

Figure 7: Campbell Diagram ${ }^{28}$ frequency range needs to be evaluated. This poses some difficulties since it can be difficult to design around such a wide range of modes. 


\section{Bearings and Fuel Leakage Flows}

As with the above mentioned turbomachinery components, the turbomachinery orifices and clearances are designed for full thrust. These flows and leakages control the amount of bearing coolant and the overall thrust balance of the turbopump. At reduced thrust levels, bearing leakages become a larger percent of the overall flow. As a result, pump efficiencies decrease as power levels are decreased.

One other consideration in this area centers around rotor speeds. As the pump speed decreases with power level, there is less radial growth of the rotating components. Thus, at lower power levels, clearances are increased, and pump efficiencies are decreased. This can also impact bearing coolant flow and turbopump thrust balance conditions, which can affect overall bearing life and manifest itself as turbopump vibration. ${ }^{29}$

\section{Stall and Velocity Triangles}

On the turbine side of the turbopump, it is important to achieve optimal efficiency, and to extract the optimal amount of work out of the driving fluid or gas. Typically, when designing a turbopump, the turbine blades are optimized to achieve the maximum amount of work through the series of turbine blades, both the rotor and stator blades, by designing to the angle of attack of the fluid. The "velocity triangles" refer to the net velocity vector of the fluid as it approaches the turbine blade, and the lift and drag components of that vector. The velocity vector changes as it moves from the first stage turbine inlet vanes, to the first stage rotor blades, to the stator vanes, and so on. When an engine is throttled and a lower fluid velocity is injected into the turbine, the velocity triangles change, and in some cases efficiency is lost due to the now non-optimal attack angle relationship to the blade geometry.

It isn't likely that a turbine would be designed specifically for the low power levels. The approach that is typically taken is to design the blades to maximum thrust operation, and the performance that is achieved at low power levels is dealt with, and the efficiency losses are taken into account in the engine system model. Flow separation occurs when the flow momentum over the blades is reduced to a certain point; flow separation can lead to stall. ${ }^{30}$ Flow separation from one blade causes a wake effect on the adjacent blade, which can lead to high loads and structural concerns. These wake effects can be compensated for by increasing the gap between the blades. Although increasing the gap reduces the blade loading, it can also lead to efficiency losses.

On the pump side, if the net velocity vector in a pump becomes too shallow, or if the ramp rate down to low power levels is too great, the pump can stall. Stall is more likely to occur on the pump side rather than the turbine side. On the turbine side, the main concern is losing efficiency. For deep throttling, the flow coefficient can fall far to the right of the head rise vs. flowrate graph, and can fall in the stall region. "The flow coefficient will fall substantially below its design value, the pump hydrodynamic flow will become highly unstable, efficiency will be poor, and greater inlet-suction pressure to the pump will be necessary to avoid cavitation." 25 It is also important to consider that when operating in a stall regime, the pressure oscillations can be nearly twice what they would be in a non-stalled regime, and can be as high as five times nominal if operating in a cavitation regime. ${ }^{25}$

One way to compensate for velocity vector variation as the power level drops is to use a splitter vane to achieve better control over the fluid velocity vector as it enters the system.

The SSME throttling was initially limited to $65 \%$ RPL due to the HPOTP preburner vane diffuser stall. Flow separation occurred in the diffuser on the preburner pump, and a high incidence angle on the diffuser vanes downstream of the impeller limited the engine throttling to $65 \%$. $^{27}$

For the RL-10 engine, the cavitating venturi valves are used in order to isolate the fuel pump from combustion chamber coolant oscillations, which also could lead to stall. ${ }^{31}$ These combustion chamber coolant oscillations are caused by fuel jacket boiling, which is discussed in the combustion chamber section of this paper. The use of the valves in this instance keeps the pressure above the critical pressure of the fuel in the coolant tubes to avoid fuel jacket boiling. As boiling is avoided, the fuel can then drive the turbine without encountering stall. This is an excellent example of the combustion chamber, cavitating venturi valve, turbine, and both pumps all being an integrated system that requires careful system design.

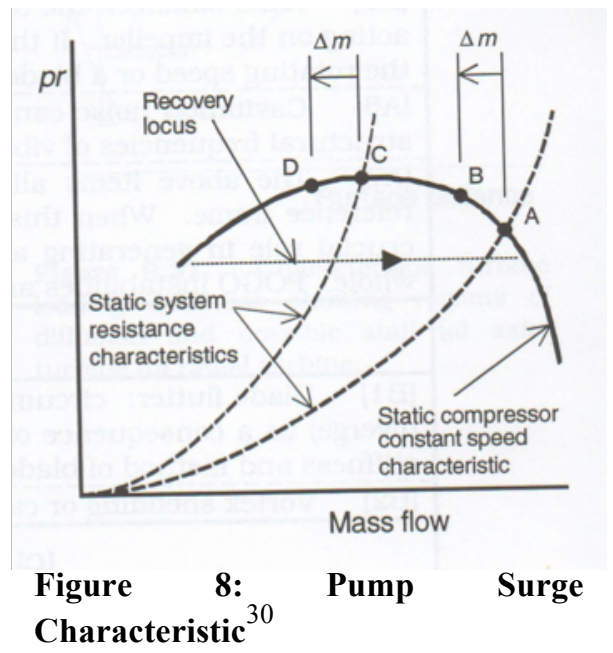




\section{Surge}

Surge is another type of pump instability that is caused by "overall mass flow oscillations through the entire hydraulic system," which can "result in severe fluctuations in inlet and discharge pressures and mass flows." ${ }^{, 32}$ It is desirable to avoid surge when possible. Surge can initiate upon reduced flowartes to the inducer, while maintaining a constant speed. Surge is a systems issue where the pump and other components interact in an unstable manner, leading to strongly coupled fluctuating flow. ${ }^{30}$ This needs to be understood and avoided when designing a throttling turbopump. This phenomenon is shown in Figure 8.

\section{F. Valves}

Main valves and ancillary valves must be adequately designed to operate over a wide range of pressures and temperatures, while still maintaining the precision and control needed over the full operating range.

When designing both the valves and the valve actuators, considerations must be made to balance the pressures across the valve as thrust is decreased or increased. If the valve slew rates or sealing capabilities cannot accommodate the required throttle range, the engine could encounter difficulties with flow control that could impact all components.

The LMDE uses cavitating venturi valves on both the oxidizer and fuel feed sides in order to control the amount of propellant flow that reaches the injector. The use of these venturi valves allows for adequate force balance on the turbopumps and isolates the feed system from injection system effects. "As the pressure drop across the venturi throat increases, a critical point is reached wherein the total upstream pressure head is converted into velocity head and fluid vapor pressure. With the inlet temperature and pressure conditions held constant, a further decrease in the downstream pressure does not cause any change in the flow rate through the venturi." ${ }^{33}$ At maximum thrust, the valve is noncavitating for a low pressure drop. As the engine is throttled (10-65\% thrust in the LMDE), the valve operates in the cavitating range and achieves hydraulic decoupling. This is shown in Figure 9.

As discussed in the combustion chamber section above, special valves can be used in order to provide enough backpressure just downstream of the coolant tubes in expander cycle engines such as the CECE. This is done in order to keep the fuel pressure in the coolant tubes above the critical pressure of the fuel.

On the CECE, turbine bypass valves are used to control the flow to the turbines. The flow bypasses the single fuel turbine in order to control the turbine speed. The amount of fluid bypassing the turbines is controlled by fuel turbine bypass valves (FTBVs).

The question arises as to how mixture ratio can be

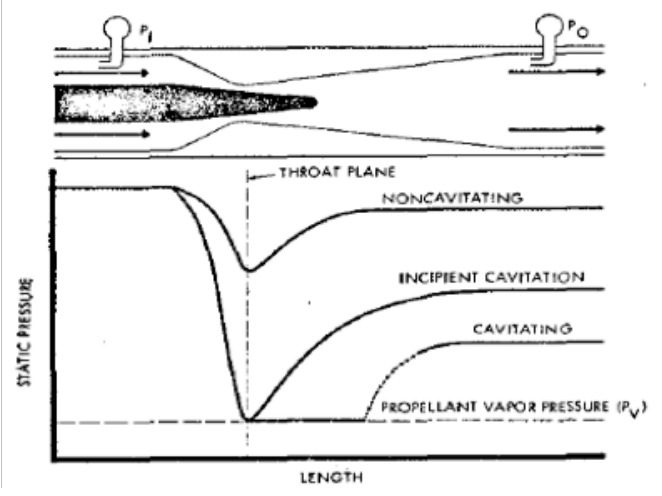

Figure 9: Typical Pressure Profile Through a Cavitating Venturi Valve $^{33}$ controlled in a throttleable engine while using a geared pump assembly. On the CECE, the OCV is just downstream of the oxidizer pump and is used to control the amount of oxidizer that is pumped to the combustion chamber. This valve acts as a "brake" on the turbopump assembly. However, the turbine still works to pump the right amount of fuel to achieve proper mixture ratio and thrust control.

\section{G. Nozzle}

The nozzle provides the necessary structure to react against the expansion of the combusted gas in order to pull as much work as possible out of the engine. The hot gases are accelerated through the throat and are expanded through the nozzle. Referring back to Equation (1), it can be seen that the relationship between exit pressure and exit area plays a role in the amount of thrust that is generated by the engine.

Nozzles can exhibit ideal expansion, over-expansion, or under-expansion. Ideal nozzle expansion occurs when $p_{e}=p_{a}$. Since in flight a rocket engine travels in a trajectory of changing altitude, and $p_{c}$ is assumed to be constant for an engine operating at steady state conditions, ideal expansion only occurs at one altitude.

When the $p_{e}$ is less than $p_{a}$, the flow is said to be over-expanded. When the $p_{e}$ is greater than $p_{a}$, the flow is said to be under-expanded. This condition is undesirable, since the maximum amount of energy is not extracted out of the hot gas, and thus potential thrust is lost. 
Flow separation is a function of "nozzle geometry, gas properties, characteristic Reynolds number, boundary layer displacement, boundary layer thickness, pressure gradients, wall temperature, and nozzle Mach number." ${ }^{34}$ It is also a function of thrust ramp rate and wall temperature. Quicker ramp rates produce lower side loads. The method for nozzle cooling also impacts the type of nozzle separation that is experienced.

Flow separation occurs when the exhaust gas detaches from the nozzle wall when the nozzle exit pressure is less than about $1 / 3$ the ambient pressure into which the nozzle is discharging. Typically, if operating at steady state, nozzle flow separation is relatively symmetric. However, during engine transients and throttling, the separation can be asymmetric, and can impose significant side loads on the nozzle. ${ }^{35}$ This is highly undesirable, but is unavoidable. Usually, a certain amount of flow separation can be tolerated; it needs to be determined on a case-by-case basis how much separation is acceptable to maintain structural integrity of the nozzle, engine, and test stand. As thrust is decreased and the flow separation moves up the nozzle, in extreme cases the throat can become un-choked, which leads to severe loss of engine performance.

Flow separation can be either Free Shock Separation (FSS) or Restricted Shock Separation (RSS). "The FSS occurs when the developing nozzle flow in the diverging section suddenly separates from the wall; since this is frequently non-axisymmetric, it will induce a "side load".," "In RSS the separated flow reattaches to the wall; again, this is usually an asymmetric event." 36 The FSS and RSS are shown in Figure 10.

SSME uses a 77.5:1 expansion ratio nozzle. The SSME nozzle is regeneratively cooled. The SSME project conducted a series of throttling tests in the mid 1990s where the thrust was ramped down to $17 \%$ thrust. One achievement that was reached during his test

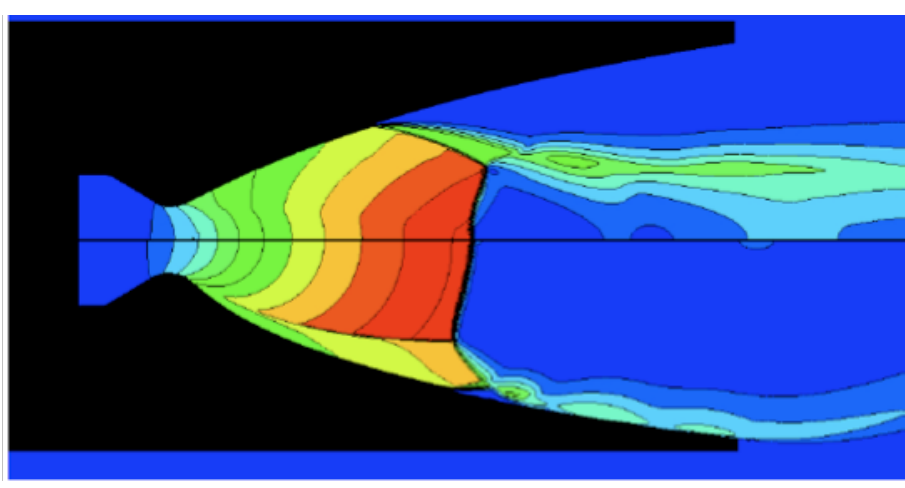

Figure 10: Free Shock Separation (top) and Restricted Shock Separation (bottom) ${ }^{36}$ series was "refined definition of nozzle flow separation heat loads." 18 When comparing to predicted values, the nozzle separation heat loads calculated from the test were about twice what was predicted at low power levels. Even though the loads were higher than predictions, minimal damage to the nozzle was experienced.

One example where damage nozzle damage was observed occurred on an RD-120 engine, which is a Russian $\mathrm{LH}_{2} / \mathrm{LO}_{2}$, staged-combustion cycle engine that achieves a maximum vacuum thrust just shy of 195,000 lbf. "When the engine was throttled from $100 \%$ thrust to $25 \%$ thrust, the shock plane moved inside the nozzle to produce a vibration force $15-25$ higher than when the engine runs at $100 \%$ thrust.. ${ }^{37} 86$ of the 480 metal fasteners holding the hatband stiffeners to the nozzle were found to be broken after the $25 \%$ thrust test.

\section{Conclusion}

The LMDE and the RL-10 derivatives (in particular CECE) have demonstrated deep throttling, while the SSME has demonstrated relatively shallow throttling. Shallow throttling is typically required for the boost phase, while deep throttling is typically required on landing and rendezvous missions such as orbital injection, landing phase, and fine thrust control applications.

Throttling methods include: high-pressure-drop injection systems using propellant flow regulation, varying injection element area by using either selectable manifolds or movable injector elements, gas injection, multiple chambers, and varying nozzle throat area. Due to throttling difficulties, alternate approaches to throttling are sometimes used such as pulse modulation, multiple engines, or vehicle design.

Throttling is an overall engine systems problem; it requires a fine balance between the injector, combustion chamber, turbomachinery, valves, and nozzle. The key difficulty in throttling liquid rocket engines is maintaining an adequate pressure drop across the injector, which is necessary to provide propellant atomization and mixing. For the combustion chamber, cooling can be an issue at low thrust levels. For turbomachinery, the primary considerations are to avoid cavitation, stall, surge, and to consider bearing leakage flows, rotordynamics, and structural dynamics. For valves, it is necessary to design valves and actuators that can achieve accurate flow control at all thrust levels. For the nozzle, it is important to assess the amount of flow separation that can be tolerated at low thrust levels for ground testing. 
Liquid rocket engine throttling has been required on past space missions, and it will be required on future missions, whether the destination is the moon, mars, or a near-Earth object. Although most of the current literature on throttling is devoted to the injector, throttling is a system issues that touches every component on the engine and the feed system. It is critical for the future of the U.S. space program to continue to study methods for throttling to better understand liquid rocket engine functionality and sensitivities, as throttling components can also be used in advanced propulsion systems such as nuclear-thermal in addition to liquid rocket engine systems.

\section{Acknowledgments}

The author would like to thank Joseph Leahy for his guidance and advice during all phases of the progression of this paper. Jason Turpin was also very helpful as a mentor and as a systems engineer to provide help in evaluating the throttling engine as a system. The time spent advising and guiding is greatly appreciated.

The author would also like to thank Matthew Casiano for his help in finding resources and discussing throttling methods in detail; Erika Alvarez and Matthew Marsh for their guidance in the turbomachinery area; Joseph Ruf and Paul Gradl for their expertise on nozzle design and flow separation; and Gregg Jones for his expertise on injector design. Everyone named above works at the NASA Marshall Space Flight Center in the Propulsion Engineering Directorate.

\section{References}

${ }^{1}$ Griffin, Michael D. and French, James R., "Launch Vehicle Selection," Space Vehicle Design, 2nd Edition, AIAA Education Series, Virginia, 2004, pp. 196, 229-235.

2 "NASA's Exploration Systems Architecture Study, Final Report," NASA-TM-2005-214062, November 2005.

3 "NASA's Fiscal Year 2011 Budget Estimates," NASA Website, www.nasa.gov, [Retrieved February 1, 2010].

${ }^{4}$ Welton, D.E., Bensky, M.S., and Hiland, J., "Variable Thrust Liquid Propellant Rocket Engines," AIAA Paper 1963-0268, June 1963.

${ }^{5}$ Sutton, George P. and Biblarz, Oscar, "Thrust Chambers," Rocket Propulsion Elements, 7th Edition, John Wiley \& Sons, Inc., New York, 2001, pp. 268-324.

${ }^{6}$ Casiano, Matther J., Hulka, James R., and Yang, Vigor, "Liquid-Propellant Rocket Engine Throttling: A Comprehensive Review," AIAA Paper 2009-5135, August 2009.

${ }^{7}$ Huzel, Dieter K. and Huang, David H., Modern Engineering for Design of Liquid-Propellant Rocket Engines, Progress in Astronautics and Aeronautics Volume 147, AIAA, Washington D.C., 1992, pp. 26, 71, 104, 106, 112, 205, $206,378$.

${ }^{8}$ Giuliano, V. J., Leonard, T. G., and Kim, T. S., "Development Status of the CECE Cryogenic Deep Throttling Demonstrator Engine," Space Propulsion 2008, 2nd International Symposium on Propulsion for Space Transportation, 2008.

${ }^{9}$ Dressler, G.A., "Summary of Deep Throttling Rocket Engines with Emphasis on Apollo LMDE," AIAA Paper 2006-5220, July 2006.

${ }^{10}$ Aerojet, “Aerojet Awarded NASA Contract for Unique LOX-Hydrogen Deep Throttling Injector Development," http://spacefellowship.com/news/art15675/aerojet-awarded-nasa-contract-for-unique-lox-hydrogen-injector.html [retrieved 1 May, 2010].

${ }^{11}$ Dressler, G.A., Bauer, J.M., "TRW Pintle Engine Heritage and Performance Characteristics," AIAA Paper 2000-3871, July 2000 .

12 Elverum, Jr., G., Staudhammer, P., Miller, J., Hoffman, A., and Rockow, R., "The Descent Engine for the Lunar Module," AIAA Paper 67-521, July 1967.

${ }^{13}$ Casiano, Matthew J., Interview on Throttling Techniques, 9 April 2010.

${ }^{14}$ Tanner, Lawrence G., "Development and Characteristics of the Russian/American RD-180 Rocket Engine," AIAA Liquid Propulsion Short Course, Presented at the AIAA Liquid Propulsion Conference, Indianapolis, IN, July 2002.

${ }^{15}$ Gilroy, R. and Sackheim, R., "The Lunar Module Descent Engine - A Historical Summary," AIAA Paper 89-2385, July 1989.

${ }^{16}$ Santiago, Jorge R., "Evolution of the RL10 Liquid Rocket Engine for a New Upperstage Application," AIAA Paper 96-3013, July 1996.

${ }^{17}$ Pugh, Richard L., "The Many Facets of the RL-10 Liquid Rocket Engine...A Continuing Success Story," AIAA Paper 983680, July, 1998.

${ }^{18}$ Harris, S.L., "Block II: The New Space Shuttle Main Engine," AIAA Paper 96-2853, 1996.

19 Biggs, R.E., "Space Shuttle Main Engine - the First Twenty Years and Beyond," American Astronautical Society History Series, Vol. 29, Univelt, San Diego, CA, 2008.

${ }^{20}$ Bradley, M. A., "SSME Off-Nominal Low Power Level Operation," AIAA Paper 1997-2685, 1997.

${ }^{21}$ Limerick, C., "Component Design Concerns for Deep Throttling $\mathrm{H}_{2} / \mathrm{O}_{2}$ Rocket Engines," AIAA Paper 91-2209, June 1991. 
${ }^{22}$ Wanhainen, John P., Antl, Robert J., Hannum, Ned P., and Mansour, Ali H., "Throttling Characteristics of a HydrogenOxygen, Regeneratively Cooled, Pump-Fed Rocket Engine," NASA TM X-1043, December 1964.

${ }^{23}$ Stepanoff, A.J., "Centrifugal and Axial Flow Pumps Theory, Design, and Application," 2nd Edition, Krieger Publishing Company, Malabar, Florida, 1957, pp.25-42, 225-233.

${ }^{24}$ Brennen, Christopher E., "Hydrodynamics of Pumps," Concepts ETI, Inc. and Oxford University Press, Norwich, Vermont, 1994, pp. 1-26, 71-84.

${ }^{25}$ Wong, G.S., Macgregor, C.A., and Hoshide, R.K., "Suppression of Cavitation and Nonstable Flow in Throttled Turbopumps," Journal of Spacecraft and Rockets, Vol. 2, No. 1, Jan.-Feb. 1965, pp. 73-80.

${ }^{26}$ Blair, J.C., Ryan, R.S., and Schutzenhofer, L.A., "Launch Vehicle Design Process: Characterization, Technical Integration, and Lessons Learned," NASA TP-2001-210992, Marshall Space Flight Center, May 2001.

${ }^{27}$ Marsh, Matthew, Interview on Turbopump Design for Variable Thrust Applications, 18 March 2010.

${ }^{28}$ Brown, A.M., "Comprehensive Structural Dynamic Analysis of the SSME/AT Fuel Pump First-Stage Turbine Blade," NASA TM-1998-208594, Marshall Space Flight Center, Alabama, 1998.

${ }^{29}$ Alvarez, Erika, Interview on Turbopump Design for Variable Thrust Applications, 16 March 2010.

${ }^{30}$ Japikse, David, and Baines, Nicholas C., "Stability ad Range," Introduction to Turbomachinery, Concepts ETI, Inc and Oxford University Press, White River Junction, Vermont, 1997, pp. 1-7 through 1-9, 2-43, and 9-1 through 9-26.

${ }^{31}$ Limerick, C.D., and Brown, J.R., "Expander Cycle Engine Applicability to Advanced Space Mission," JANNAF Paper, May 1989.

${ }^{32}$ Greitzer, E.M., "The Stability of Pumping Systems - The 1980 Freeman Scholar Lecture," Journal of Fluids Engineering, Vol. 103, June 1981, pp. 193-242.

${ }^{33}$ Harvey, D.W., "Throttling Venturi Valves for Liquid Rocket Engines," AIAA Paper 70-0703, June 1970.

${ }^{34}$ Fuller, P.N., "J-2S Nozzle Side-Load Study Final Report," NASA Contract NAS8-25156, August 1972.

${ }^{35}$ Sutton, G.P., History of Liquid Propellant Rocket Engines, AIAA, Reston, VA, 2006, pp. 93-94, 184-186, 483-485, 505-508.

${ }^{36}$ Brown, Andrew M., Ruf, Joseph H., and McDaniels, David M., "Recovering Aerodynamic Side Loads on Rocket Nozzles using Quasi-Static Strain-Gage Measurements," AIAA Paper 2009-2681, 2009.

${ }^{37}$ Rachuk, V. S., Shostak, A. V., Dmitrenko, A. I., Goncharov, G. I., Hernandez, R., Starle, R. G., and Hulka, J., "Benchmark Testing of an Enhanced Operability LO2/LH2 RD-0120 Engine," AIAA Paper 96-2609, 1996. 